\title{
Suppression of pulmonary innate host defence in smokers
}

\author{
C Herr, ${ }^{1}$ C Beisswenger, ${ }^{1}$ C Hess, ${ }^{1}$ K Kandler, ${ }^{1}$ N Suttorp, ${ }^{2}$ T Welte, ${ }^{3}$ J-M Schroeder, ${ }^{4}$ \\ C Vogelmeier, ${ }^{1} \mathrm{R}$ Bals for the CAPNETZ Study Group ${ }^{1}$
}

${ }^{1}$ Department of Internal Medicine, Division for Pulmonary Diseases, Philipps-Universtät Marburg, Marburg, Germany; ${ }^{2}$ Department of Internal Medicine/Infectious Diseases, Charité, Universitätsmedizin, Berlin, Germany; ${ }^{3}$ Department of Internal Medicine, Division for Pulmonary Diseases,

Medizinische Hochschule Hannover, Hanover, Germany; ${ }^{4}$ Clinical Research Unit at the Department of Dermatology, University Hospital SchleswigHolstein, Campus Kiel, Kiel, Germany

Correspondence to: Professor R Bals, Department of Internal Medicine, Division of

Pulmonology, Hospital of the University of Marburg,

Baldingerstrasse 1, 35043

Marburg, Germany; bals@

mailer.uni-marburg.de

The first two authors contributed equally.

Received 4 June 2008 Accepted 23 September 2008 Published Online First 13 October 2008

\author{
ABSTRACT \\ Background: Smoking increases the susceptibility to \\ pulmonary infection and is a risk factor for the \\ development of chronic obstructive pulmonary disease \\ (COPD). It is postulated that cigarette smoke suppresses \\ the activation of the innate immune system in response to \\ bacterial infection.
}

Methods: Using sensitive ex vivo analysis, the level of the endogenous antibiotic peptide human $\beta$-defensin- 2 (hBD-2) was measured in pharyngeal washing fluid and sputum from patients with community acquired pneumonia. The regulation of antibacterial host defence molecules was studied in vitro. The effect of cigarette smoke on the antibacterial activity of differentiated airway epithelium and the expression of host defence molecules was studied in an in vitro infection model.

Results: Current or former smoking was associated with significantly reduced hBD-2 levels in pharyngeal washing fluid and sputum from patients with acute pneumonia. Exposure of airway epithelium to smoke in vitro inhibited the induction of hBD-2 by bacteria. This correlated with decreased antimicrobial activity. This effect was mimicked by hydrogen peroxide, and catalase blunted the smokeinduced inhibition of epithelial host defence.

Conclusions: Smoke exposure suppresses the induction of epithelial antibacterial host defences. These findings link smoking with increased susceptibility to infection. This mechanism may be important in the pathogenesis of pneumonia and COPD.

Cigarette smoking and exposure to environmental tobacco smoke increase the risk of pulmonary infections in general and the risk to contract invasive pneumococcal disease by a factor of $4.1{ }^{1}$ In addition, other pulmonary infections are more frequent in smokers including influenza and tuberculosis. ${ }^{2}$ A population-based case-control study revealed that the risk of community acquired pneumonia (CAP) attributable to the consumption of any type of tobacco was $32.4 \%$ in patients with chronic obstructive pulmonary disease (COPD). ${ }^{3}$ Animal experiments have shown that smoke exposure results in decreased host defence of the lung. Cigarette smoke applied to mice for 68 weeks resulted in a delayed rate of bacterial clearance compared with sham-exposed animals. ${ }^{4}$ Smoke decreases the function of mucociliary clearance, ${ }^{5}$ promotes adhesion of bacteria to the airway epithelia ${ }^{6}$ and affects the function of pulmonary host defence cells. ${ }^{7}$

Cigarette smoke is the most important risk factor for the development of COPD. COPD is a chronic progressive lung disease with a large medical and economic burden that develops in approximately $15-20 \%$ of all smokers. The pathogenesis of COPD is not clear. Chronic smoke exposure results in an inflammatory process characterised by the presence of neutrophils, macrophages and CD8+ lymphocytes. Detailed morphological analysis of tissue samples from patients with COPD revealed the presence of lymphoid aggregates containing follicles in the peripheral airways. ${ }^{8}$ Recurrent or chronic infections may be a driving force in the development of COPD. Smoking and COPD are related to bacterial colonisation of the pulmonary tract. Rising airway bacterial load is associated with greater airway inflammation and an accelerated decline in forced expiratory volume in $1 \mathrm{~s} .{ }^{9}$ The diversity of the local microflora appears to change during the development of COPD. ${ }^{10}$ One hypothesis to describe the progression of COPD includes chronic or recurrent infections of the airways with subsequent activation of innate and adaptive immune mechanisms.

The innate host defence system of the lung is a first-line protection system. Antimicrobial peptides (AMPs) are important effector molecules of the innate immune system. ${ }^{11}$ The defensins and cathelicidins are the principal families of AMPs that are expressed in the respiratory tract. The $\beta$ defensins are mainly produced by epithelial cells and are secreted onto the airway surface where they have a broad spectrum of antimicrobial activity. In vitro studies and clinical studies show that the expression of several AMPs is induced by bacterial products and inflammatory mediators. ${ }^{11}{ }^{12}$

The aim of the present study was to characterise the effect of smoking on functions of innate host defences and to correlate findings from clinical studies with results from in vitro experiments.

\section{METHODS}

\section{Patients from CAPNETZ}

CAPNETZ is the German Community Acquired Pneumonia Network that investigates the epidemiology, microbiology and clinical course of CAP (www.capnetz.de). ${ }^{13}$ Patients are identified by clinical signs and a positive lung radiograph. The programme was approved by local ethics committees and informed consent was obtained from the patients.

The material used for the study was obtained from 27 consecutive patients with CAP for whom the necessary samples (pharyngeal washing fluid, sputum) were available. The characteristics of the patients are summarised in table 1. Reformed smokers are defined as being abstinent for 12 months; other groups are never smokers and current smokers. Pharyngeal washing fluid was 
Table 1 Patient characteristics

\begin{tabular}{lllll}
\hline Item & Current smokers & Former smokers & Never smokers & p Value \\
\hline $\mathrm{N}$ & 12 & 6 & 9 & - \\
Mean (SD) age (years) & $49.9(12.8)$ & $70.9(14.6)$ & $67.0(14.6)$ & 0.002 \\
Sex (M/F) & $7 / 5$ & $4 / 2$ & $5 / 4$ & NS \\
Mean (SD) CRB-65 & $0.3(0.5)$ & $1.2(0.4)$ & $1.1(0.6)$ & 0.004 \\
Mortality & 0 & 0 & 0 & - \\
\hline
\end{tabular}

$\mathrm{p}$ values were calculated using one-way ANOVA.

CRB-65, severity score for community acquired pneumonia; NS, not significant.

collected from 10 non-smoking and 10 smoking individuals with no current symptoms of infections by rinsing the mouth and gargling for $10 \mathrm{~s}$. Pharyngeal washing fluid was used because the procedure can be performed non-invasively in sick patients and the material is suitable for the applied assays. It is commonly used to test for pathogens in lower airway infection. ${ }^{14}$

\section{Measurement of human $\beta$-defensin-2 concentrations and Western blotting}

Levels of the endogenous antibiotic peptide human $\beta$-defensin-2 (hBD-2) in pharyngeal washings obtained from patients were measured using an ELISA that detects hBD-2 in a range of 0.15 $12.5 \mathrm{ng} / \mathrm{ml}$. 96-well microtitre plates (Nunc, Wiesbaden, Germany) were coated with a polyclonal antibody ${ }^{15}$ against hBD-2 in $50 \mathrm{mM}$ carbonate/bicarbonate buffer ( $\mathrm{pH}$ 9.6) and the plates were blocked with $1 \%$ gelatin/PBS. $100 \mu$ of samples were added into each well and incubated overnight at $4^{\circ} \mathrm{C}$. A series of seven dilutions of recombinant $\mathrm{hBD}-2^{15}$ was included as standard. Wells were washed and incubated with $100 \mu \mathrm{l}$ of a second polyclonal antibody against hBD-2 $(0.5 \mu \mathrm{g} / \mathrm{ml} \mathrm{AB} 9871$, Abcam, Cambridge, UK) and subsequently with $100 \mu \mathrm{l}$ of a horseradish peroxidase (HRP)-labelled anti-goat antibody (1:40000, SigmaAldrich, Munich, Germany). Wells were washed again and $100 \mu \mathrm{TMB}+$ substrate solution (Dako, Carpinteria, California, USA) was added and incubated for $10 \mathrm{~min}$. $100 \mu \mathrm{l}$ stop solution $\left(\mathrm{H}_{2} \mathrm{SO}_{4}, 3 \mathrm{~N}\right)$ was added and the optical density of each well was determined using a microplate reader set to $450 \mathrm{~nm}$. For test evaluation, spiking experiments were performed (recovery 79-81\%).

Sputum from patients with pneumonia was analysed for hBD-2 by Western analysis. Samples were normalised to the weight of the initial sputum probe and measurements of protein before loading revealed equivalent protein quantities with a small variation (SD $<15 \%$ of the mean). $10 \mu$ complete protease inhibitor cocktail (Roche, Mannheim, Germany) was added per $1 \mathrm{mg}$ sample. To homogenise the sample, $10 \mu \mathrm{l}$ 100 mM 1,4-dithiothreit (DTT, Roth, Karlsruhe, Germany) were added per $100 \mathrm{mg}$ of sputum. Five samples from smokers and five from non-smokers were pooled, extracted with $0.1 \%$ trifluoroacetic acid (TFA) and 10\% acetonitrile. The material was applied to Sep-Pak Plus C18 cartridges (Waters, WAT020515, Milford, USA) and eluted with $0.1 \%$ TFA and $80 \%$ acetonitrile. The eluate was dried in a speed-vac concentrator and reconstituted in $20 \mu \mathrm{l}$ distilled water. The extraction procedure of $\mathrm{hBD}-2$ from sputum was validated by spiking experiments using commercially available hBD-2 peptide (Abcam). The detection limit was $2.5 \mathrm{ng}$ hBD-2. The samples were separated on a 10-20\% tris-tricine gel (Anamed, Darmstadt, Germany) and blotted on nitrocellulose membranes using Dunn-Carbonate buffer in a tank-blotting system (BioRad Laboratories, Hercules, California, USA). For autoradiographic detection a polyclonal $\mathrm{hBD}-2$ antibody ${ }^{15}$ and an
HRP-labelled secondary rabbit-IgG antibody (GE-Healthcare, Little Chalfont, UK)) were used.

\section{Cells and tissue culture, bacterial strain}

Human bronchial epithelial cells were isolated from large airways resected during surgery and cultivated as submersed or air-liquid interface cultures as described previously. ${ }^{16}$ Donors (42, 39, 53 years of age) underwent lung transplantation for pulmonary fibrosis. The results did not differ between cells from the donors. The protocol was approved by the ethics committee of the University of Marburg and informed consent was obtained from the patients. Pseudomonas aeruginosa PAO1 bacteria were grown to an $\mathrm{OD}_{600}=1.00$ in $\mathrm{LB}$ media. For experiments with heat-inactivated bacteria, dilutions of $10^{7} \mathrm{col}-$ ony-forming units $(\mathrm{CFU}) / \mathrm{ml}$ were prepared in phosphatebuffered saline (PBS) and incubated for $30 \mathrm{~min}$ at $96^{\circ} \mathrm{C}$. Experiments with viable bacteria were performed using a dilution of $10^{5} \mathrm{CFU} / \mathrm{ml}$ in $\mathrm{PBS}$. $P$ aeruginosa was used as a model organism because it is known to colonise the respiratory tract of patients with COPD and is sensitive to epithelial host defence factors. The number of CFUs used to infect cells was determined by plating an aliquot of the inoculum and varied between experiments.

\section{Smoke exposure and infection models}

Tissue cultures were exposed to volatile cigarette smoke as described previously. ${ }^{17}$ Briefly, tissue cultures were exposed to cigarette smoke for $15 \mathrm{~min}$ (3 cigarettes). After exposure the medium of the cultures was immediately replaced. Control cultures were incubated in the exposure chamber for the same time period without burning a cigarette. To determine the effects of cigarette smoke on the expression and release of hBD2 and interleukin (IL)-8, heat-inactivated $P$ aeruginosa PAO1 $\left(10^{7} \mathrm{CFU} / \mathrm{ml}\right.$ in $\left.30 \mu \mathrm{l}\right)$ was applied to the apical side of the cultures for $8 \mathrm{~h}$.

To investigate the effects of reactive oxygen species on the $\beta$ defensin expression in airway epithelium, cells were incubated with or without hydrogen peroxide for $1 \mathrm{~h}$. After exposure the medium was replaced and the cells were stimulated with heatinactivated $P$ aeruginosa PAO1 $\left(10^{7} \mathrm{CFU} / \mathrm{ml}\right)$ for $8 \mathrm{~h}$. Catalase (Sigma-Aldrich, Steinheim, Germany) was added to the culture medium at a concentration of $6400 \mathrm{U} / \mathrm{ml}$ immediately before and after smoke exposure.

\section{Bacterial survival assays}

The apical surface of differentiated epithelium was exposed to the smoke as described. After smoke exposure the cells were infected with $1 \times 10^{4-5} \mathrm{CFU}$ viable $P$ aeruginosa in $15 \mu \mathrm{PBS}$. To determine the numbers of viable bacteria $6 \mathrm{~h}$ after infection, the apical surfaces of the cultures were washed with $100 \mu \mathrm{IPBS}$ and serial dilutions were plated onto LB agar plates. $5 \mu$ recombinant hBD-2 in $200 \mu 1^{18}$ was applied to the apical surfaces of the 
cultures in some experiments based on concentrations calculated for airway secretions. ${ }^{19}$

\section{Cytokine measurements}

Levels of human IL-8 in tissue culture medium were determined by commercially available ELISAs according to the manufacturer's instructions (R\&D Systems, Wiesbaden-Nordenstadt, Germany)

\section{Quantitative PCR}

RNA isolation, reverse transcription and quantitative PCR were performed as described elsewhere. ${ }^{17}$ GAPDH primer (sense, $5^{\prime}$ GAAGGTGAAGGTCGGAGTC-3'; antisense, 5'-GAAGATGG TGATGGGATTTC-3'), hBD-1 primer (sense, 5'-GCCTCAG GTGGTAACTTTCTCA-3'; antisense 5'-GCGTCATTTCTTC TGGTCACT-3') and hBD-2 primer (sense $5^{\prime}$-TCAGCTCC TGGTGAAGCTC-3'; antisense 5'-GGGCAAAAGACTGGA TGACA-3') were purchased from TIB Molbiol (Berlin, Germany).

\section{Statistical methods}

Values are displayed as mean (SD). Comparisons between groups were analysed by $t$ test or ANOVA for experiments with more than two subgroups. Post hoc range tests were performed with the $t$ test with Bonferroni adjustment. $p$ Values $<0.05$ were considered statistically significant.

\section{RESULTS}

\section{Epithelial defensin levels in smokers with CAP}

To determine whether smokers have decreased levels of mucosal AMPs in their airway secretions, we measured the amount of hBD-2 in pharyngeal flushing fluid and sputum from 27 patients with CAP by ELISA. Significantly decreased concentrations of hBD-2 were found in pharyngeal flushing fluid from current smokers and former smokers compared with never smokers (fig 1A). Healthy never-smoking and healthy current-smoking controls showed low levels of defensin. In a next step we analysed whether hBD-2 is present in the sputum of these patients. Owing to its physical properties, sputum could not be used for ELISA and therefore hBD-2 was analysed by Western blotting in extracts of pooled sputum samples. No sputum was available from healthy controls. hBD-2 was present in the sputum of never-smoking patients. In contrast, no peptide was found in the sputum of patients with CAP who were current smokers (fig 1B). It is likely that Western blotting is not sensitive enough to reveal small differences as determined by ELISA. These data show that epithelial antimicrobial defensins are induced during pneumonia and that current and former smoking suppresses this induction.

\section{Effect of smoke exposure on the induction of epithelial defensin by bacteria}

The effect of volatile cigarette smoke on the response of differentiated primary bronchial airway to $P$ aeruginosa was investigated. Smoke-exposed cells showed decreased antimicrobial activity resulting in significantly increased numbers of viable bacteria after infection with $P$ aeruginosa (fig 2A). Treatment of the cells with volatile cigarette smoke did not cause an increase in the release of lactate dehydrogenase (data not shown).

To investigate whether this defect of epithelial host defence after smoke exposure is correlated with decreased production of defensin, hBD-2 expression levels were measured after smoke exposure and in control cells. Smoke-exposed airway epithelium showed significantly suppressed hBD-2 mRNA induction in response to bacterial stimulation with heat-inactivated $P$ aeruginosa (fig $2 \mathrm{~B}$ ). The expression of $\mathrm{hBD}-1$ was not regulated under the applied conditions (fig $2 \mathrm{~B}$ ). The suppressed induction of $\mathrm{hBD}-2$ expression correlated with a decrease in $\mathrm{hBD}-2$ peptide secretion (fig 2C). Exogenously applied purified hBD-2 peptide significantly reduced the number of recovered bacteria from
Figure 1 Effect of smoking on the mucosal host defence system in patients with community acquired pneumonia (CAP). The concentration of human $\beta$ defensin-2 (hBD-2) peptide was measured in pharyngeal washing fluid from patients with CAP by ELISA. (A) Current or former smokers had decreased levels of the antimicrobial peptide hBD-2 in their pharyngeal washings compared with never smokers; numbers of patients $=10$, $6,12,6$, and 9 for the healthy nonsmokers, healthy smokers, current smokers, former smokers and never smokers (last three groups with CAP), respectively. $p=0.0024$ (ANOVA) with ${ }^{*} p<0.05 ;{ }^{*} p<0.01$ for Bonferroni post hoc test where indicated. (B) Proteins were extracted from sputum as described in the Methods section, pooled and separated by SDS-gel electrophoresis and blotted onto nitrocellulose. In never smokers, hBD-2 was present in the size of the active form (arrow). hBD-2 was not detectable in current smokers. The blot is representative of several experiments and shows pooled material from five individuals.

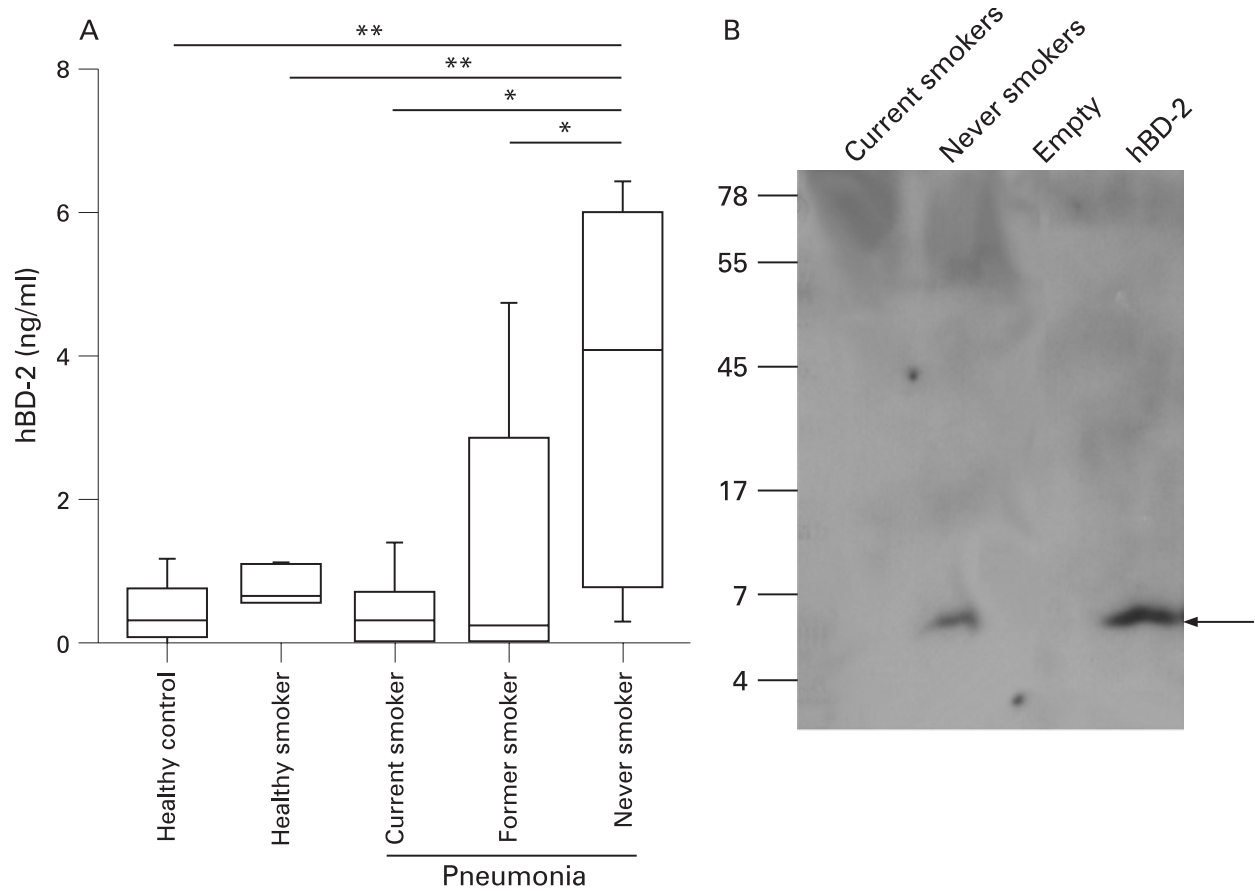


Figure 2 Smoke exposure of differentiated airway epithelium resulted in a breach of epithelial host defence. Cell cultures were exposed to cigarette smoke (CS) and subsequently infected with $1 \times 10^{5}$ viable $P$ aeruginosa (PA0). The data in panels $A-C$ were obtained from the same experiment. (A) Exposure to CS reduced antimicrobial activity of epithelial cells. Washes from the apical surface were prepared $6 \mathrm{~h}$ after infection and the number of viable bacteria determined. (B) Exposure to CS suppressed the induction of human $\beta$-defensin-2 (hBD-2) by bacteria. hBD-1 and hBD-2 mRNA levels were determined by quantitative RT-PCR. (C) hBD-2 peptide concentration in apical washings was measured by ELISA and found to be significantly decreased after exposure to CS. (D) Exogenously applied hBD-2 (5 $\mu \mathrm{g}$ per well) was added to infected smoke-exposed cells and restored the epithelial antimicrobial activity. Cells, untreated controls; PAO, infected cells; CS, smoke-exposed cells; CFU, colony-forming units. $\mathrm{n}=8$ per group. ${ }^{*} p<0.05$; ${ }^{* *} p<0.01$; ${ }^{* *} p<0.001$ ( $t$ test).
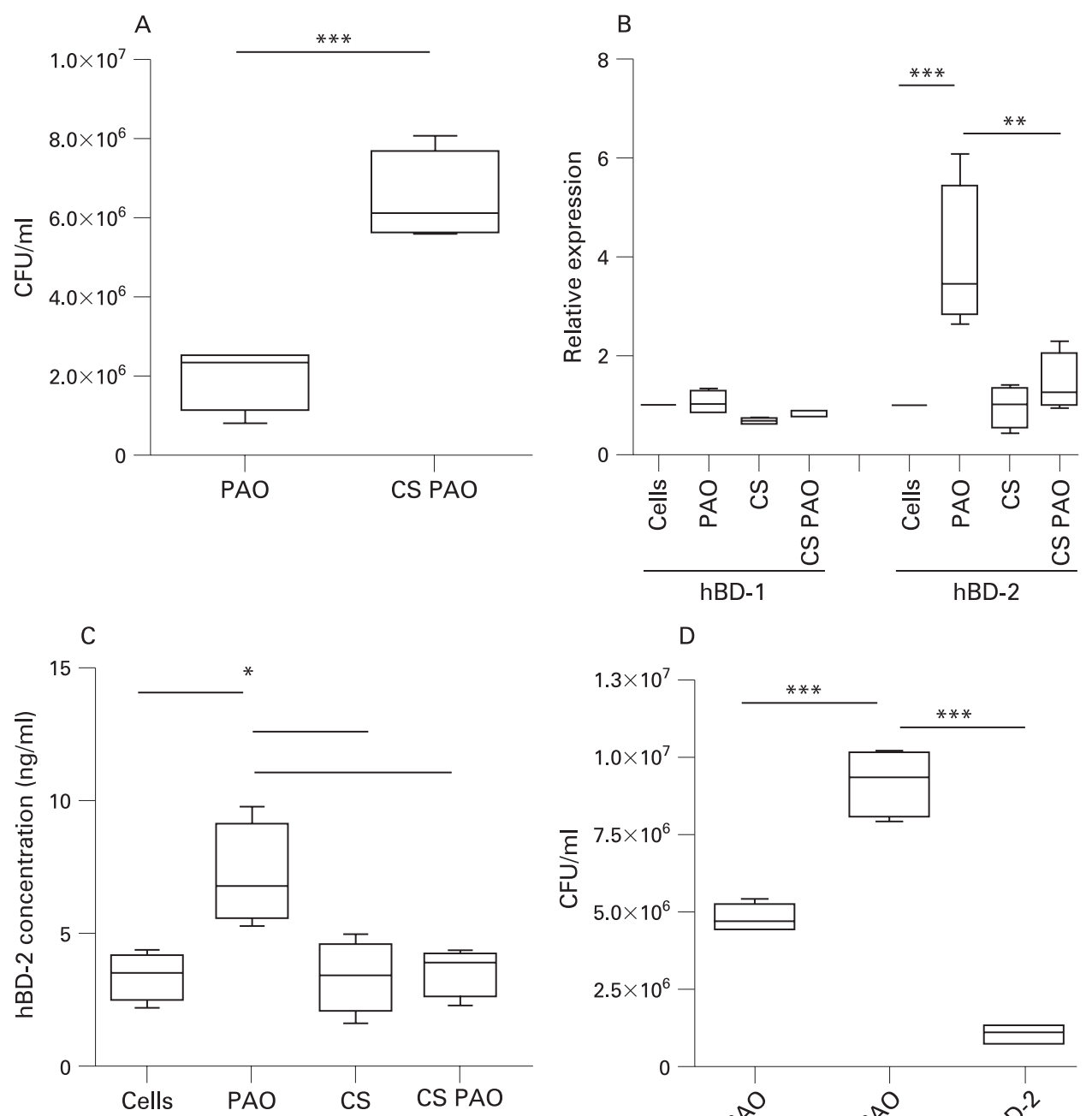

smoke-exposed and infected cells (fig 2D). Additional experiments showed that most viable bacteria were washed off by the procedures and that the bacteria attached to the cells did not influence the results (data not shown). Despite variations in the number of CFUs in the inoculum applied in individual experiments, the outcomes were qualitatively equivalent.

To test whether reactive oxygen species are involved in the mechanisms of defensin suppression, hydrogen peroxide was applied before exposing the airway epithelium to bacteria. Significant suppression of hBD-2 mRNA induction by heatinactivated $P$ aeruginosa occurred (fig $3 \mathrm{~A}$ ) without an increase in the release of lactate dehydrogenase from these cells (data not shown). The use of catalase as an antioxidant partly abrogated the effects of cigarette smoke on the induction of hBD-2 expression (fig 3B).

To test whether smoke exposure resulted in a general decrease in cellular responses, we measured the release of IL-8 after exposure to smoke and heat-inactivated bacteria. The combination of smoke exposure and administration of $P$ aeruginosa resulted in increased release of IL-8 (fig 3C).

\section{DISCUSSION}

The main finding of this study is that cigarette smoke suppresses the activation of the epithelial innate host defence system of the lung. Oxidative stress appears to play a role because hydrogen peroxide exposure mimics the suppressive effect of cigarette smoke and antioxidant treatment weakens this effect. Defensin appears to have a specific role in this mechanism because its expression correlates with host defence in tissue culture and clinical samples. External application of the peptide hBD-2 restored antimicrobial activity.

An increasing body of data supports the role of defensins in pulmonary host defence. In vitro experiments have shown wide antimicrobial activity ${ }^{20}$ and animal studies with mice deficient in mouse $\beta$-defensin 1 ( $\mathrm{mBD}-1$ ) found increased susceptibility to infection. ${ }^{21} 22$ The number of defensin gene copies varies between individuals (copy number variants). Individuals with low numbers of gene copies of the defensin locus are predisposed to Crohn's disease. ${ }^{23}$ It is known that smoking alters the function of host defence components of the lung. Smoke-exposed animals also have increased inflammation but delayed clearance of $P$ aeruginosa after infection. ${ }^{4}$ In addition, host defences against respiratory syncytial virus appear to be suppressed after exposure to smoke. ${ }^{24}$

The mechanism by which cigarette smoke causes a breach in the host defence is unclear. Cigarette smoke is known to inhibit the function of professional immune and host defence cells such as dendritic cells, ${ }^{25} \mathrm{~T}$ cells ${ }^{26}$ and alveolar macrophages. ${ }^{27}$ In this 

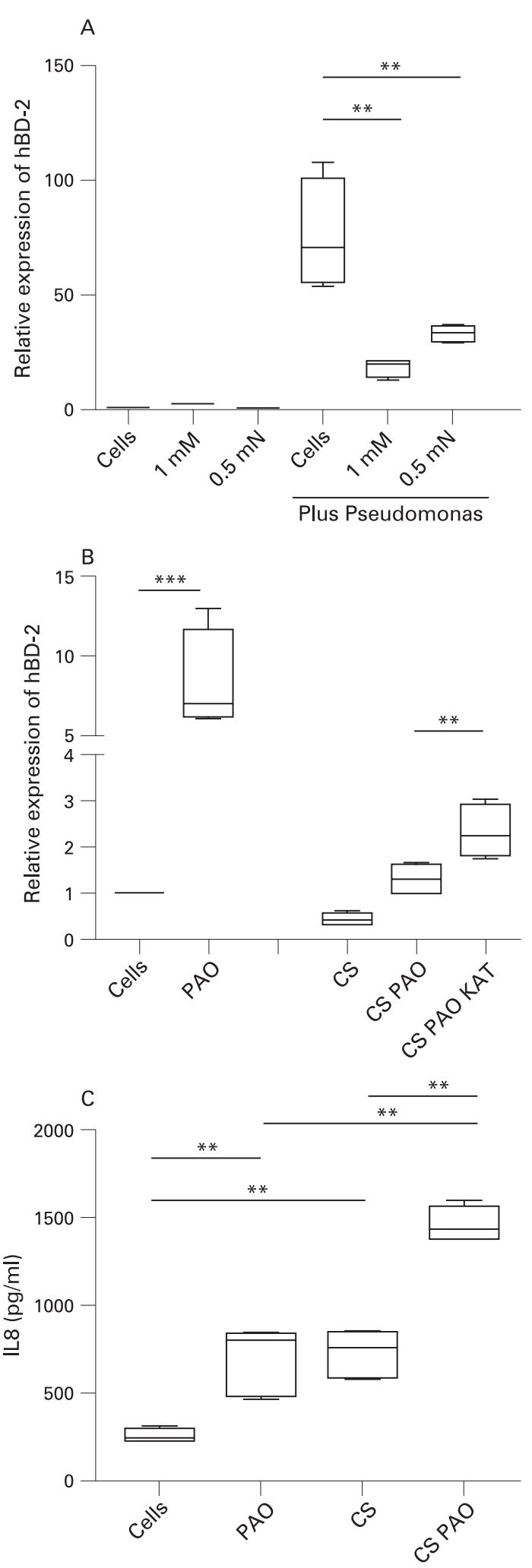

Figure 3 Effect of oxidative stress on the smoke-dependent inhibition of epithelial antimicrobial activity. (A) Human $\beta$-defensin-2 (hBD-2) induction by application of $1 \times 10^{7}$ colony-forming units (CFU)/ml heatinactivated $P$ aeruginosa (PAO) was inhibited by hydrogen peroxide $(1 \mathrm{~h}$ preincubation with the indicated concentrations). (B) Application of catalase (KAT) added immediately before exposure to cigarette smoke (CS) partly restored the suppressive effect of CS on hBD-2 expression. (C) Exposure to CS and PAO increased the release of interleukin (IL)-8. $\mathrm{n}=8$ per group, ${ }^{* *} \mathrm{p}<0.01$; ${ }^{* *} \mathrm{p}<0.001$ ( $t$ test for $\mathrm{A}$ and $\mathrm{B}$, ANOVA for C; $p<0.0001$, Bonferroni post hoc test where indicated). study we also show that the host defence function of airway epithelium is compromised by cigarette smoke. Smokers with pneumonia had significantly lower levels of hBD-2 in their mucosal secretion. Epithelial cells are the main cellular source of hBD-2 in the lung. ${ }^{15}$ Th2-biased inflammation during atopic dermatitis is correlated with decreased levels of AMPs and skin infections. ${ }^{28}$ We have shown that smoke exposure decreases epithelial host defences in the pulmonary system. In the study population, current smoking was associated with a lower age and less severe pneumonia. The mechanistic interaction between these factors and their impact on AMP expression is largely unclear.

Interestingly, the release of the proinflammatory cytokine IL8 from epithelial cells is synergistically increased by the combination of smoke exposure and bacterial infection. In parallel, the host defence function and the expression of hBD-2 are decreased. Smokers have decreased levels of host defence peptide and the amount of inflammation in COPD is correlated with the magnitude of the bacterial load. ${ }^{9}$ Smoke is generally thought to affect proinflammatory pathways including MAP kinases p38, ERK1/2 and JNK or NF-kB. ${ }^{17}$ Acrolein is a major product of organic combustion and inhibits NF- $\mathrm{\kappa B}$ activation by interaction with IkappaB kinase (IKK). ${ }^{29}$ The smoke component acrolein inhibits the baseline expression of IL- 8 and hBD-2 in sinonasal epithelial cells. ${ }^{30}$ Smoke also inhibits lipopolysaccharide-induced production of inflammatory cytokines by suppression of the activation of activator protein-1 in bronchial epithelial cells. ${ }^{31}$ Downregulation in TLR4 mRNA and protein expression in an epithelial cell line by cigarette smoke extract also could contribute to the effect of smoke on hBD-2 expression. ${ }^{32}$ Our data provide evidence that reactive oxygen species are involved in this process. Hydrogen peroxide could mimic the effect of smoke in epithelial host defence and catalase significantly increased the expression of hBD-2. The absence of lactate dehydrogenase release in our studies excluded frank cell necrosis. Apoptosis is a further mechanism that could result from smoke exposure. ${ }^{33}$ The increased production of IL-8 after smoke exposure showed that the effect of smoke on defensin expression is not due to an overall decrease in cell viability. The effect of smoke components on various signaling processes results in the differential expression of individuals genes as shown here for IL-8 and hBD-2.

The clinical implication of smoke-induced inhibition of pulmonary defences and the subsequent susceptibility to infection is obvious. In addition, a breach in innate host defence probably contributes to the pathogenesis of COPD. This chronic inflammatory lung disease is correlated with colonisation and increased bacterial load. A further feature of COPD is a selfperpetuating inflammatory process. Consistent with these findings, depression of hBD-2 induction was also found in former smokers who had stopped smoking more than 12 months previously. Smoke-induced decreased endogenous host defences might lead to an altered microflora of the lungs with increased numbers of microorganisms. Smoke is also known to break down the epithelial barrier that is essential for providing a physical barrier for microorganisms and limiting a host defence reaction. ${ }^{34}$ The combination of a broken epithelial barrier and the presence of microorganisms could results in a vicious cycle of inflammation, structural damage and infection. The contribution of antibacterial host defence molecules in this process has been suggested by an association study that showed that a genetic variation of human beta-defensin 1 (hBD-1) is found more frequently in patients with COPD than in controls. ${ }^{35}$ 
In conclusion, exposure to smoke reduces epithelial host defence, potentially resulting in increased susceptibility to colonisation and infection. This mechanism is probably involved in increased susceptibility to pulmonary infection.

Acknowledgements: The authors thank the CAPNETZ Study Group for making samples and data available for the study, and Thomas Damm for excellent technical support.

Funding: Supported by grants from the Deutsche Forschungsgemeinschaft (Ba 1641/ 8-1;SBF/TR 22) to RB and from the German Federal Ministry of Education and Research (Bundesministerium für Bildung und Forschung, BMBF) via CAPNETZ to RB (01KI0432), NS (01KI0426) and TW (01KI0429).

Competing interests: None.

Ethics approval: The study was approved by local ethics committees and informed consent was obtained from the patients.

\section{REFERENCES}

1. Nuorti JP, Butler JC, Farley MM, et al. Cigarette smoking and invasive pneumococcal disease. Active Bacterial Core Surveillance Team. N Engl J Med 2000;342:681-9.

2. Arcavi L, Benowitz NL. Cigarette smoking and infection. Arch Intern Med 2004;164:2206-16.

3. Almirall J, Gonzalez CA, Balanzo X, et al. Proportion of community-acquired pneumonia cases attributable to tobacco smoking. Chest 1999;116:375-9.

4. Drannik AG, Pouladi MA, Robbins CS, et al. Impact of cigarette smoke on clearance and inflammation after Pseudomonas aeruginosa infection. Am J Respir Crit Care Med 2004;170:1164-71.

5. Foster WM, Langenback EG, Bergofsky EH. Disassociation in the mucociliary function of central and peripheral airways of asymptomatic smokers. Am Rev Respir Dis 1985;132:633-9.

6. Raman AS, Swinburne AJ, Fedullo AJ. Pneumococcal adherence to the buccal epithelial cells of cigarette smokers. Chest 1983;83:23-7.

7. Hodge S, Hodge G, Ahern J, et al. Smoking alters alveolar macrophage recognition and phagocytic ability: implications in chronic obstructive pulmonary disease. Am J Respir Cell Mol Biol 2007;37:748-55.

8. Hogg JC, Chu F, Utokaparch $\mathrm{S}$, et al. The nature of small-airway obstruction in chronic obstructive pulmonary disease. N Engl J Med 2004;350:2645-53.

9. Wilkinson TM, Patel IS, Wilks $\mathrm{M}$, et al. Airway bacterial load and FEV 1 decline in patients with chronic obstructive pulmonary disease. Am J Respir Crit Care Med 2003;167:1090-5.

10. Sethi S, Evans N, Grant BJ, et al. New strains of bacteria and exacerbations of chronic obstructive pulmonary disease. N Engl J Med 2002;347:465-71.

11. Bals R. Roles of antimicrobial peptides in pulmonary disease. In: Devine DA, Hancock RE, eds. Mammalian host defence peptides. 1st ed. Cambridge: Cambridge University Press, 2004:349-74.

12. Harder J, Meyer-Hoffert U, Teran LM, et al. Mucoid Pseudomonas aeruginosa, TNFalpha, and IL-1beta, but not IL-6, induce human beta-defensin-2 in respiratory epithelia. Am J Respir Cell Mol Biol 2000;22:714-21.

13. Welte T, Suttorp N, Marre R. CAPNETZ-community-acquired pneumonia competence network. Infection 2004;32:234-8.
14. Lieberman D, Shleyfer E, Castel H, et al. Nasopharyngeal versus oropharyngeal sampling for isolation of potential respiratory pathogens in adults. J Clin Microbiol 2006;:44:525-8.

15. Bals R, Wang $X$, Wu Z, et al. Human beta-defensin 2 is a salt-sensitive peptide antibiotic expressed in human lung. J Clin Invest 1998;102:874-80.

16. Bals R, Beisswenger $C$, Blouquit $S$, et al. Isolation and air-liquid interface culture of human large airway and bronchiolar epithelial cells. J Cyst Fibros 2004;3(Suppl 2):49-51.

17. Beisswenger $\mathbf{C}$, Platz J, Seifart C, et al. Exposure of differentiated airway epithelial cells to volatile smoke in vitro. Exp Lung Res 2004;71:402-9.

18. Harder J, Bartels J, Christophers E, et al. A peptide antibiotic from human skin. Nature 1997;:387:861.

19. Chen CIU, Schaller-Bals S, Paul KP, et al. Beta-defensin and LL-37 in bronchalveolar lavage fluid of patients with cystic fibrosis. J Cyst Fibros 2004;3:45-50.

20. Zasloff M. Antimicrobial peptides of multicellular organisms. Nature 2002:415:389-95.

21. Moser C, Weiner DJ, Lysenko $E$, et al. beta-Defensin 1 contributes to pulmonary innate immunity in mice. Infect Immun 2002;70:3068-72.

22. Morrison G, Kilanowski F, Davidson D, et al. Characterization of the mouse beta defensin 1, Defb1, mutant mouse model. Infect Immun 2002;70:3053-60.

23. Fellermann $\mathbf{K}$, Stange DE, Schaeffeler $\mathrm{E}$, et al. A chromosome 8 gene-cluster polymorphism with low human beta-defensin 2 gene copy number predisposes to Crohn disease of the colon. Am J Hum Genet 2006;79:439-48.

24. Phaybouth V, Wang SZ, Hutt JA, et al. Cigarette smoke suppresses Th1 cytokine production and increases RSV expression in a neonatal model. Am J Physiol Lung Cell Mol Physiol 2006;290:L222-31

25. Vassallo R, Tamada K, Lau JS, et al. Cigarette smoke extract suppresses human dendritic cell function leading to preferential induction of Th-2 priming. J Immunol 2005; 175:2684-91

26. Glader P, Moller S, Lilja J, et al. Cigarette smoke extract modulates respiratory defence mechanisms through effects on T-cells and airway epithelial cells. Respir Med 2006;100:818-27.

27. Droemann D, Goldmann T, Tiedje T, et al. Toll-like receptor 2 expression is decreased on alveolar macrophages in cigarette smokers and COPD patients. Respir Res 2005;6:68.

28. Ong PY, Ohtake T, Brandt C, et al. Endogenous antimicrobial peptides and skin infections in atopic dermatitis. N Engl J Med 2002;347:1151-60.

29. Valacchi G, Pagnin E, Phung A, et al. Inhibition of NFkappaB activation and IL-8 expression in human bronchial epithelial cells by acrolein. Antioxid Redox Signal 2005; 7:25-31.

30. Lee WK, Ramanathan M Jr, Spannhake EW, et al. The cigarette smoke component acrolein inhibits expression of the innate immune components IL-8 and human betadefensin 2 by sinonasal epithelial cells. Am J Rhinol 2007;21:658-63.

31. Laan M, Bozinovski S, Anderson GP. Cigarette smoke inhibits lipopolysaccharideinduced production of inflammatory cytokines by suppressing the activation of activator protein-1 in bronchial epithelial cells. J Immunol 2004;173:4164-70.

32. MacRedmond RE, Greene CM, Dorscheid DR, et al. Epithelial expression of TLR4 is modulated in COPD and by steroids, salmeterol and cigarette smoke. Respir Res 2007:8:84

33. Tagawa Y, Hiramatsu N, Kasai A, et al. Induction of apoptosis by cigarette smoke via ROS-dependent endoplasmic reticulum stress and CCAAT/enhancer-binding protein-homologous protein (CHOP). Free Radic Biol Med 2008:45:50-9.

34. Burns AR, Hosford SP, Dunn LA, et al. Respiratory epithelial permeability after cigarette smoke exposure in guinea pigs. J Appl Physiol 1989;66:2109-16.

35. Matsushita I, Hasegawa K, Nakata K, et al. Genetic variants of human betadefensin-1 and chronic obstructive pulmonary disease. Biochem Biophys Res Commun 2002:291:17-22.

\section{BMJ Masterclasses}

BMJ Masterclasses are educational meetings designed specifically to meet the learning needs of doctors. They help doctors keep up to date with the latest evidence and recent guidelines in major clinical areas, enabling them to use the latest evidence to make better decisions. The latest evidence, recent guidelines and best practice are delivered in an interactive and informative manner by leading experts. The speakers are specifically chosen as highly-skilled communicators who can authoritatively enthuse the audience and interpret the latest research and guidelines into practical tips for busy doctors. BMJ Masterclasses have proved a huge hit with clinicians, with many saying they have influenced their clinical practice.

http://masterclasses.bmj.com/ 